\title{
Precipitation Polymerization of 2-Methylene-1,3-dioxepane in Supercritical Carbon Dioxide
}

\author{
By Soyoung KWON, ${ }^{1}$ Kyoungwon LEE, ${ }^{1}$ Won BAE, ${ }^{2}$ and Hwayong $\mathrm{KIM}^{1, *}$
}

Free radical homopolymerization experiments were conducted with 2-methylene-1,3-dioxepane in supercritical carbon dioxide $\left(\mathrm{scCO}_{2}\right)$ using a heterogeneous precipitation polymerization method and AIBN as the initiator. We also synthesized copolymers of 2-methylene-1,3-dioxepane with $N$-vinyl-2-pyrrolidone. The influence of comonomer feed ratios on the yield, glass transition temperature $\left(T_{\mathrm{g}}\right)$ and copolymer composition was investigated. The copolymers produced were characterized by ${ }^{1} \mathrm{H}$ NMR, FT-IR spectroscopy and DSC. Reactivity ratios of comonomer in the initial step of the precipitation copolymerization process were estimated from copolymer composition analysis. In addition, we investigated the effect of reaction temperature on the reactivity ratios and determined that the reactivity ratios slightly increased and that MDOP had a larger deviation of reactivity ratio than that of NVP with the increased temperature. And the fine sub-micron sized copolymer particles containing with various comonomer ratios were prepared by aerosol solvent extraction system (ASES).

KEY WORDS: Biodegradable Polymer / 2-Methylene-1,3-dioxepane / Precipitation Polymerization / Supercritical Carbon Dioxide / $N$-Vinyl-2-pyrrolidone / ASES /

Widely varying biodegradable and biocompatible polymers have been sought and subsequently developed as biomaterials to use for controlled release drug delivery systems, in tissue engineering and as absorbable sutures. ${ }^{1-4}$ Biodegradable aliphatic polyesters are usually synthesized by ring-opening polymerization (ROP) in bulk or in solution. ${ }^{1-7}$ Ionic ring opening polymerization is commonly used to synthesize poly ( $\varepsilon$-caprolactone) (PCL) which is an aliphatic polyester often used for biomedical applications. Catalysts for ionic ROP are not easily managed due to their sensitivity to water. The ringopening for the ester can be increased by activation of a $\mathrm{Zn}$ or Sn-based catalyst with the carbonyl ester. However, the introduction of a catalyst risks the introduction of traces of potentially cytotoxic material. ${ }^{8} \mathrm{~A}$ few catalysts have been approved by the U. S. Food and Drug Administration that are used for biomedical applications. ${ }^{1-8}$

2-Methylene-1,3-dioxepane (MDOP), which is among of the cyclic ketone acetals, can polymerized by free radical ringopening method to produce PCL in commonly used radical initiators. MDOP also proceed with $100 \%$ ring opening for polymer and easily copolymerize with vinylic monomers such as styrene, $N$-isopropylacrylamide, methyl acrylate and methyl methacrylate, and so on using AIBN as a thermal radical initiator. ${ }^{9-12}$ These resulting copolymers have degradable caprolactone (CL) units in their molecular backbones.

Supercritical carbon dioxide $\left(\mathrm{scCO}_{2}\right)$ is considered to be a useful alternative to toxic or volatile organic solvents for polymer synthesis and processing. ${ }^{13-15}$ The main advantages to using $\mathrm{scCO}_{2}$ as a polymerization medium include less toxicity, non-flammability, chemically inertness and naturally abundance compared to organic solvents. In addition, $\mathrm{scCO}_{2}$ is removed by simple depressurization and the density of the solvent can be controlled by varying pressure. ${ }^{13-15}$ These properties may lead to many advantages to environmentally friendly polymers to demand high purity. Due to the low solubility of most polymers in $\mathrm{scCO}_{2}$, it is generally expected that most polymerizations results in precipitation with very low yield and molecular weight. However, special stabilizers to overcome these disadvantages in other polymerization methods (dispersion and emulsion polymerization etc.) cannot be easily removed from final polymer. That may affect final product purity. Especially it is important issues in fields of biocompatible materials.

In the studies to be reported on, free radical ring-opening homo- and copolymerization of 2-methylene-1,3-dioxepane (MDOP) using $N$-vinyl-2-pyrrolidone (NVP) products were synthesized in $\mathrm{scCO}_{2}$. Poly ( $N$-vinyl-2-pyrrolidone) (PVP) has very low toxicity, high complexing ability, and excellent film forming and desirable adhesive properties. Collectively, these characteristics are utilized in hair sprays, adhesives, photographic and lithographic coatings, and so on. ${ }^{16,17}$ PVP has been especially used in such fields as cosmetics (detergents, soaps, hair spraying agents, dyes), medical devices (ophthalmic, lubricious coating, biocompatible coatings and complex), and for pharmaceuticals (controlled release, bind agents, stabilizers for polymerization and as thickeners) because of excellent biocompatibility properties. ${ }^{4,18}$ PVP has variable glass transition temperatures as the molecular weight of the polymer increases $\left(M_{\mathrm{w}}=9,000\left(109^{\circ} \mathrm{C}\right) \sim 1,200,000\left(179^{\circ} \mathrm{C}\right)\right) .{ }^{18,19}$ Polymer processing temperatures increase because of high glass transition temperatures. On the other hand, PMDOP has a low glass transition temperature ${ }^{20}$ and weak mechanical

\footnotetext{
${ }^{1}$ School of Chemical and Biological Engineering and Institute of Chemical Processes, Seoul National University, San 56-1, Shilim-dong, Gwanak-Gu, Seoul, 151-744, Korea

${ }^{2}$ R\&D Institute, Miwon Commercial Co., Ltd, Ansan 425-100, Korea

*To whom correspondence should be addressed (Tel: +82-2-880-7406, Fax: +82-2-888-6695, E-mail: hwayongk@snu.ac.kr).
} 
strength. These properties are taken advantage in blending or copolymerization with other polymers to modify the flexibility of the finished polymer product.

Copolymers involving NVP and MDOP can improve mechanical and thermal properties as well as provide some biodegradable attributes and control of bioactive molecule release. These copolymers can be used for biomaterials by excellent biocompatibility and biodegradability. Specific copolymerization of NVP and MDOP in organic solvent was identified previously (U.S. patent 5,912,312 granted in 1998). ${ }^{21}$ Although the patent defined copolymerization and characterization in solution and precipitation of the final polymerized product, the compositional ranges of NVP and MDOP were limited (60-99 mol \% of NVP and 1-40 mol \% of MDOP; preferably $85-95 \mathrm{~mol} \% \mathrm{NVP}$ and $5-10 \mathrm{~mol} \%$ MDOP). Further, the reported monomer reactivity ratio was not measured experimentally and it was calculated from Q, e values in reference data. The estimation of copolymerization reactivity ratios is interested area to both academic society and industry. Knowledge of a copolymer's composition is an important factor in the evaluation of its utility. But there are a few reports to measure the comonomer reactivity ratios in $\mathrm{scCO}_{2}$ because of experimental difficulty.

The free radical ring-opening homo- and copolymerization of 2-methylene-1,3-dioxepane (MDOP) with $\mathrm{N}$-vinyl-2-pyrrolidone (NVP) synthesized using an environmentally friendly supercritical fluid process is the basis of this report. The structure of the copolymer and the effects of co-monomer ratio on glass transition temperatures were characterized by ${ }^{1} \mathrm{H}$ NMR, FT-IR and DSC. Reactivity ratios of the comonomer in the initial step of precipitation copolymerization were estimated from copolymer composition analysis. And, we have investigated the effects of reaction temperature on monomer reactivity ratio. In addition, using aerosol solvent extraction system (ASES) ${ }^{22-24}$ among the supercritical antisolvent processes $^{25,26}$ the copolymers were prepared with fine particles. Then $\mathrm{CO}_{2}$ was used as the antisolvent.

\section{EXPERIMENTAL}

\section{Materials}

2-Methylene-1,3-dioxepane (MDOP, min. 98\%) was obtained from Fluka and used without further purification. $\mathrm{N}$ vinyl-2-pyrrolidone (NVP) was kindly supplied by BASF Korea and used as received. 2,2'-azobisisobutyronitrile (AIBN, Junsei Chemical, min. 98\%) was recrystallized from methanol. Carbon dioxide (min. 99.99\%) was purchased from Korea Industrial Gases. Conventional poly ( $\varepsilon$-caprolactone) (PCL, $M_{\mathrm{w}}=180,000$, PDI $\left.=1.6\right)$ was obtained from Honam Petrochemical Corporation. Organic solvents (chloroform, hexane, heptane and dichloromethane) were used as received from Aldrich.

\section{Homopolymerization of MDOP in Bulk and in $\mathrm{scCO}_{2}$}

Homopolymerization of MDOP to characterize the purified polymer was carried out in bulk and $\mathrm{scCO}_{2}$ phase. The experimental system and equipment used in these studies is identical to that employed in our previous reported work. ${ }^{27,28}$ The internal volume of an SUS 316 polymerization reactor approximated $30 \mathrm{~mL}$ and the reactor was designed with a window to enable observations. To polymerize in bulk, monomer $(4 \mathrm{~g})$ and initiator (AIBN) ( $2 \mathrm{wt} \%$ as monomer) were added to an autoclave equipped with a PTFE coated magnetic stirring bar. The reactor was purged several times with $\mathrm{N}_{2}$ to remove residual air. The mixture was stirred at $55^{\circ} \mathrm{C}$ for $20 \mathrm{~h}$. This polymerization in bulk phase is to confirm the structure of homopolymer. The precipitation polymerization of MDOP in the $\mathrm{scCO}_{2}$ phase was carried out using the same reactor. After the monomer $(4 \mathrm{~g})$ and AIBN (1 wt \% of monomer) were injected to the reactor, the reactor was purged several times using $\mathrm{N}_{2}$ and $\mathrm{CO}_{2}$ to remove any residual air. The $\mathrm{CO}_{2}$ was charged with a gas booster pump operating at room temperature. The temperature of the reactor was gradually raised to the desired reaction temperature $\left(70^{\circ} \mathrm{C}\right)$ and then filled with $\mathrm{CO}_{2}$ until the polymerization condition (300 bars) was reached by using the booster pump, and then held for $48 \mathrm{~h}$. After the polymerization step, the reactor was cooled slowly to room temperature and $\mathrm{CO}_{2}$ slowly vented through two glass traps. To prevent the discharge of unreacted monomer to the atmosphere during $\mathrm{CO}_{2}$ separation, the glass traps were filled with cold methanol. The resulting wax-like polymers (in bulk and in $\mathrm{scCO}_{2}$ ) were washed with hexane to remove unreacted monomer and the polymer finally dried in vacuo overnight at room temperature.

\section{Copolymerization of NVP and MDOP in $\mathrm{scCO}_{2}$}

Copolymerization of MDOP with NVP was carried out using the same reactor and experimental procedures as for the homopolymerization of MDOP in $\mathrm{scCO}_{2}$. In an initial polymerization step at $70^{\circ} \mathrm{C}$ and $300 \mathrm{bar}$, the reactant mixture was dissolved and homogeneous in $\mathrm{scCO}_{2}$. That was detectable by front window. After completion of polymerization, all resulting polymers were dissolved in chloroform and redispersed using hexane and heptane mixture to wash unreacted monomer, and then collected by vacuum filtration. Copolymers were dried in vacuo overnight at room temperature to a constant weight. Comonomer conversion to copolymers was determined by gravimetric analysis. Apparatus and experimental procedures of ASES process were reported in our previously research. ${ }^{29}$ Dichloromethane (DCM) was used as solvent and $\mathrm{scCO}_{2}$ was used as antisolvent in ASES process. Process temperature, pressure, solution flow rate and solvent flow rate can effect on final particle size. In this work, especially the effect of comonomer concentrations on the size of particles after ASES process was investigated at fixed experimental conditions (pressure, temperature and the solution and solvent flow rate). The raw polymer particle was prepared at $70{ }^{\circ} \mathrm{C}$ and 300 bar during $48 \mathrm{~h}$. Total comonomer weight was $4 \mathrm{~g}$ and $1 \mathrm{wt} \%$ of AIBN on comonomer weight was used.

\section{Characterization}

${ }^{1} \mathrm{H} \mathrm{NMR}$ (Bruker, $300 \mathrm{MHz}$, and $\mathrm{CDCl}_{3}$ as a solvent) and 


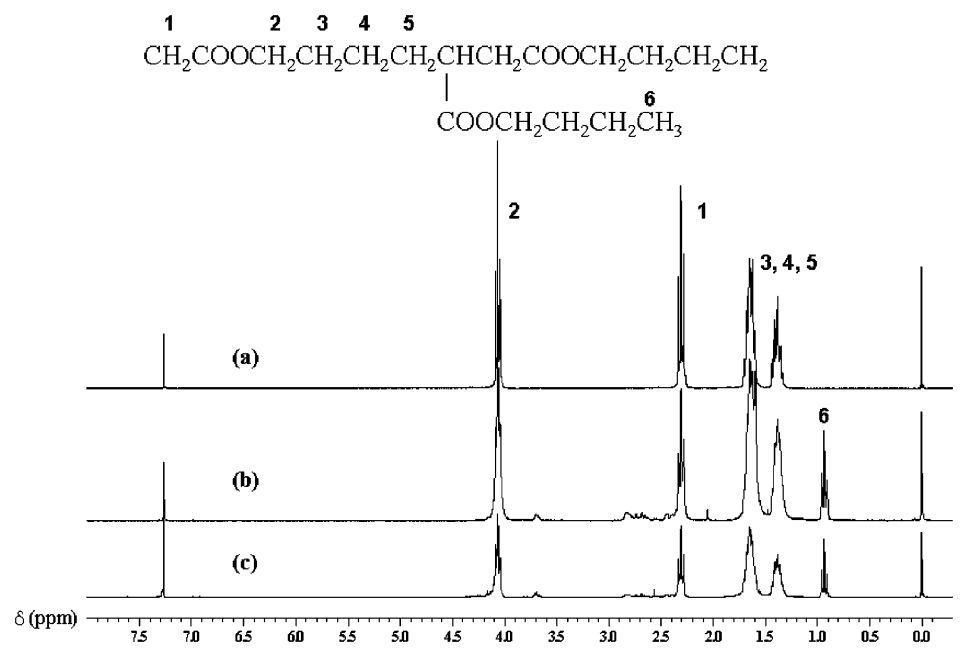

Figure 1. ${ }^{1} \mathrm{H}$ NMR spectra of homopolymers in $\mathrm{CDCl}_{3}$ : (a) $\mathrm{PCL}$, (b) PMDOP in bulk polymerization, (c) PMDOP in $\mathrm{scCO}_{2}$.

FT-IR (JASCO Model FT-IR 200, $\mathrm{KBr}$ as an internal reference) were used to confirm the chemical structure of homo- and copolymers. The thermal properties of the polymers were investigated using differential scanning calorimetry (DSC, TA instrument 2920 DSC, heating and cooling rate of $10^{\circ} \mathrm{C} / \mathrm{min}$ ) and thermogravimetric analysis (TGA, TA instrument $2050 \mathrm{TGA}$, heating rate of $20^{\circ} \mathrm{C} / \mathrm{min}$ ) in $\mathrm{N}_{2}$. Molecular weights and the distribution of homopolymer were determined by gel permeation chromatography (GPC, Waters, 600E controller) using a RI detector (Waters, 410) and three different columns (Styragel ${ }^{\circledR}$ HT2, HT3, HT4); chloroform as eluent was used at $35^{\circ} \mathrm{C}$. A narrow molecular weight distribution (MWD) PMMA was used as a standard for calibration. The monomer reactivity ratios for copolymerization of NVP and MDOP were determined from monomer feed ratios and copolymer compositions by ${ }^{1} \mathrm{H}$ NMR spectra. After ASES processing the powder samples were observed with field emission scanning electron microscope (FE-SEM, JSM6700F). Feret's diameter of 50 particles per experiment was measured from FE-SEM images.

\section{RESULTS AND DISCUSSION}

\section{Homopolymerization of MDOP in Bulk and $\mathrm{scCO}_{2}$}

The chemical structure of the homopolymer was characterized by ${ }^{1} \mathrm{H}$ NMR and FT-IR. The ${ }^{1} \mathrm{H}$ NMR spectrum of PMDOP synthesized in $\mathrm{scCO}_{2}$ compared with that of commercial PCL and PMDOP in a bulk state are shown in Figure 1. The major peaks for these three samples were identical. The ${ }^{1} \mathrm{H}$ NMR spectrum of the homopolymer of MDOP showed peaks at 1.4, 1.6, 2.3 and $4.0 \mathrm{ppm}$; the assignment of each peak is shown in Figure 1. These values were exactly same as found in the reference data. ${ }^{20,30}$ Small peaks $(0.89 \mathrm{ppm})$ in PMDOP, unlike the commercial PCL, may be caused by a different polymerization mechanism for MDOP accompanied by branching. ${ }^{20}$ The FT-IR spectra of PCL and PMDOP indicated a $\mathrm{C}=\mathrm{O}$ stretching peak at $1732 \mathrm{~cm}^{-1}$ (Figure 2). The molecular weight and polydispersity index (PDI) of PMDOP and PCL were

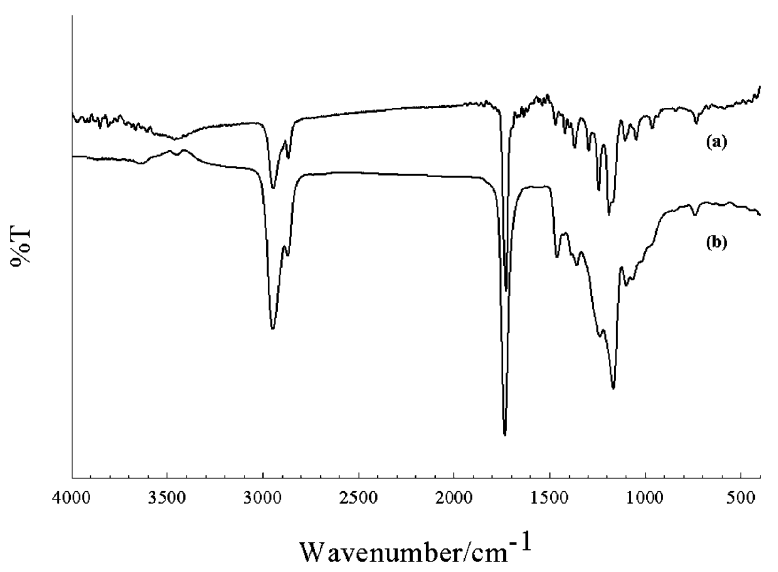

Figure 2. FT-IR spectra of homopolymers: (a) PCL, (b) PMDOP in $\mathrm{scCO}_{2}$.

Table I. Homo-polymerization of MDOP

\begin{tabular}{ccccrcc}
\hline solvent & $\begin{array}{c}\mathrm{T} \\
{\left[{ }^{\circ} \mathrm{C}\right]}\end{array}$ & $\begin{array}{c}\mathrm{P} \\
{[\mathrm{bar}]}\end{array}$ & $\begin{array}{c}\text { Conversion } \\
{[\%]^{\mathrm{c}}}\end{array}$ & $M_{\mathrm{w}} / \mathrm{PDI}^{\mathrm{d}}$ & $\begin{array}{c}T_{\mathrm{g}} \\
{\left[{ }^{\circ} \mathrm{C}\right]^{\mathrm{e}}}\end{array}$ & $\begin{array}{c}\text { Branching density } \\
{[\%]^{\dagger}}\end{array}$ \\
\hline bulk $^{\mathrm{a}}$ & $55 \pm 0.5$ & 1 & 20 & $439,000 / 9.7$ & -60 & 29 \\
$\mathrm{CO}_{2}{ }^{\mathrm{b}}$ & $70 \pm 0.5$ & $300 \pm 5$ & 37 & $11,000 / 1.5$ & -61 & 23 \\
\multicolumn{2}{r}{ Poly ( $(\varepsilon$-caprolactone) } & $(\mathrm{PCL})^{\mathrm{g}}$ & $180,000 / 1.6$ & -61 & - \\
\hline
\end{tabular}

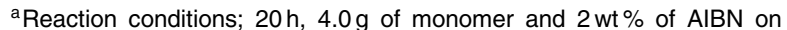
monomer. ${ }^{\mathrm{b}}$ Reaction conditions; $48 \mathrm{~h}, 4.0 \mathrm{~g}$ of monomer and $1 \mathrm{wt} \%$ of AIBN on monomer. ${ }^{\mathrm{c}} \mathrm{As}$ determined by gravimetric measurement. ${ }^{\mathrm{d}} \mathrm{As}$ determined by GPC analysis (standard materials: narrow molecular weight distribution PMMA), PDI (polydispersity index $=M_{w} / M_{n}$ ). ${ }^{\text {e As determined }}$ by TA instrument 2920 DSC (scan rate: $10^{\circ} \mathrm{C} / \mathrm{min}$ in $\mathrm{N}_{2}$ gas, second heating scan, temperature range: from -90 to $180^{\circ} \mathrm{C}$ ). ${ }^{\dagger} \mathrm{As}$ determined by calculation of relative integral area by ${ }^{1} \mathrm{H}$ NMR analysis. ${ }^{9}$ commercial PCL obtained from Honam petrochemical corporation.

determined by GPC using narrow molecular weight distribution PMMA as standard material as shown in Table I. The average molecular weight and PDI of PMDOP synthesized in $\mathrm{scCO}_{2}$ were much smaller than those in bulk phase. Both of bulk polymerization of MDOP and precipitation polymerization in $\mathrm{scCO}_{2}$ can offer the minimum contamination of the product. However, bulk polymerization is difficult to control temper- 
ature because of causing the gel effect. ${ }^{31}$ The viscosity of the reaction system increases rapidly and then, relatively strong stirring equipment is needed. The final polymer has a broadened molecular weight distribution (MWD) by chain transfer to polymer. ${ }^{31}$ PMDOP obtained from bulk phase also had high average molecular weight $\left(M_{\mathrm{w}}=439,000\right)$ and much broadened MWD (PDI =9.7). The control of molecular weight is essential for the practical application of a polymerization process. ${ }^{31}$ However, it is not easy to control the molecular weight and MWD due to autoaccelerated property by bulk polymerization. Solution or heterogeneous polymerization method can be alternative for controlling them, and then especially precipitation polymerization in $\mathrm{scCO}_{2}$ can be spotlighted due to lacking of the residual solvent. PMDOP synthesized in $\mathrm{scCO}_{2}$ had proper average molecular weight and narrow MWD in comparison with those in bulk phase. The molecular weight of PMDOP polymerized in $\mathrm{scCO}_{2}$ may be easily controlled by various experimental factors such as the concentration of monomer or initiator, system pressure and temperature and so on.

A glass transition temperature $\left(T_{\mathrm{g}}\right)$ of PMDOP polymerized in $\mathrm{scCO}_{2}$ was determined as $-61^{\circ} \mathrm{C}$. No melting peak was observed in the DSC thermogram in temperature range from -90 to $180^{\circ} \mathrm{C}$. The basis for the disappearance of $T_{\mathrm{m}}$ compared with commercial PCL $\left(T_{\mathrm{g}}=-63^{\circ} \mathrm{C}\right.$ and $T_{\mathrm{m}}=$ $58^{\circ} \mathrm{C}$ ) likely resulted from decreasing the crystallinity of PMDOP by a branching mechanism. ${ }^{20}$ And PMDOP carried out in $\mathrm{scCO}_{2}$ had a lowered molecular weight compared with reference data $\left(M_{\mathrm{w}}=72,000\right) .{ }^{20}$ The $T_{\mathrm{g}}$ of a homopolymer generally increases with increasing molecular weight up to some limiting value and known as the limiting or persistent $T_{\mathrm{g}}$ value. $^{21,32}$ Branching causes a disordering of the polymer structure thereby decreasing crystallinity. ${ }^{20,33}$ The degree of branching is presented by branching density in Table I, which can be calculated from NMR peaks (integral of $\mathrm{CH}_{3}$ peak (0.89 ppm) from branch and $\mathrm{CH}_{2}$ peak (2.3 ppm) from linear polyester). The high branching density effects on the crystallinity of the polymer, which typically the crystallinity decreases. Calculated branching densities of PMDOP in bulk phase and in $\mathrm{scCO}_{2}$ were $29\left(T_{\mathrm{g}}=-60^{\circ} \mathrm{C}\right)$ and $23 \%\left(T_{\mathrm{g}}=\right.$ $-61{ }^{\circ} \mathrm{C}$ ) respectively. In conclusion, $T_{\mathrm{g}}$ of PMDOP synthesized in $\mathrm{scCO}_{2}$ was lower than the reported value (at $-57^{\circ} \mathrm{C}$ ) for PMDOP with a higher molecular weight $\left(M_{\mathrm{w}}=72,000\right)$ and relatively lower degree of branching $(20 \%){ }^{20}$ This activity affects the $T_{\mathrm{g}}$ of homopolymer as well as thermal stability. The thermal stability of commercial PCL and PMDOP by TGA data is shown in Figure 3. The decomposition temperature for PMDOP was similar to that of PCL, however was more broaden.

\section{Copolymerization of NVP and MDOP in $\mathrm{ScCO}_{2}$}

Copolymers of NVP and MDOP were synthesized in $\mathrm{scCO}_{2}$ and characterized for composition of final copolymers by calculation of NMR spectra, yields by gravimetric method and $T_{\mathrm{g}}$ by DSC data, the results are summarized in Table II. The reaction temperature and pressure were kept the same for all

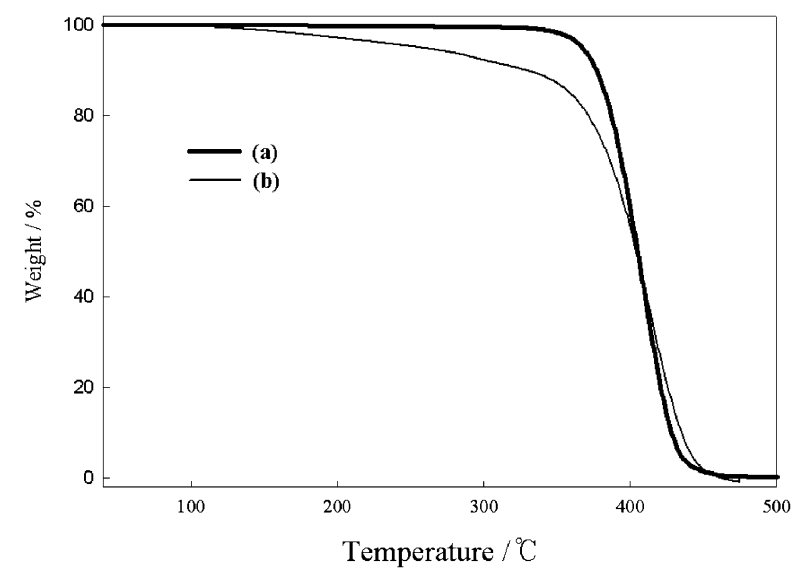

Figure 3. Thermogravimetric analysis curves for: (a) PCL, (b) PMDOP in $\mathrm{ScCO}_{2}$.

Table II. Precipitation copolymerization of NVP and MDOP in $\mathrm{scCO}_{2}{ }^{a}$

\begin{tabular}{cccccr}
\hline Entry & $\begin{array}{c}\text { NVP in feed } \\
\left(\mathrm{f}_{\text {NVP }}, \mathrm{mol} \%\right)\end{array}$ & $\begin{array}{c}\text { MDOP in feed } \\
(\mathrm{mol} \%)\end{array}$ & $\begin{array}{c}\text { Yield } \\
(\%)^{\mathrm{c}}\end{array}$ & $\begin{array}{c}\text { NVP in copolymer } \\
\left(\mathrm{F}_{\mathrm{NVP}}, \mathrm{mol} \%\right)^{\mathrm{d}}\end{array}$ & $\begin{array}{c}T_{\mathrm{g}} \\
\left({ }^{\circ} \mathrm{C}\right)^{\mathrm{e}}\end{array}$ \\
\hline 1 & 100 & 0 & $\sim 99.9$ & 100 & 146 \\
2 & 80.6 & 19.4 & 98.4 & 92.4 & 49 \\
3 & 60.4 & 39.6 & 74.9 & 83.3 & 25 \\
4 & 40.4 & 59.6 & 55.3 & 74.7 & 8 \\
$5^{\mathrm{b}}$ & 20.4 & 79.6 & 21.2 & 62.4 & -53 \\
$6^{\mathrm{b}}$ & 0 & 100 & 37.0 & 0 & -61 \\
\hline
\end{tabular}

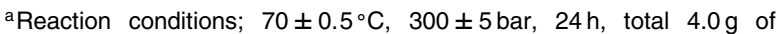
comonomer and $1 \mathrm{wt} \%$ of AIBN on comonomer. ${ }^{\mathrm{b}}$ Reaction time: $48 \mathrm{~h}$. ${ }^{\mathrm{c}}$ As determined by gravimetric measurement. ${ }^{\mathrm{d}}$ As determined by calculation of relative integral area by ${ }^{1} \mathrm{H}$ NMR analysis. ${ }^{\mathrm{e}}$ As determined by TA instrument $2920 \mathrm{DSC}$ (scan rate: $10^{\circ} \mathrm{C} / \mathrm{min}$ in $\mathrm{N}_{2}$ gas, second heating scan, temperature range: from -90 to $180^{\circ} \mathrm{C}$ ).

reactions $\left(70^{\circ} \mathrm{C} ; 300 \mathrm{bar}\right)$. The $T_{\mathrm{g}}$ data for copolymers are located between the $T_{\mathrm{g}}$ of a homopolymer of NVP and MDOP. The $T_{\mathrm{g}}$ data of copolymers are proposed to be random copolymers with a single glass transition temperature and is closer to the $T_{\mathrm{g}}$ of the higher component that is present in the copolymer. The results of copolymerization showed good miscibility of two polymers. The morphologies of resulting copolymers were changed to fine particles, wax-like sticky lump and viscous liquid as MDOP contents increase in copolymer. The TGA data of homopolymers and copolymer is showed in Figure 4. A small weight loss (about 5\%) under $100^{\circ} \mathrm{C}$ in TGA curve of PVP homopolymer may be residual water contents because of the absorb ability of PVP. The weight loss of the poly (NVP-co-MDOP) containing $37.6 \mathrm{~mol} \%$ of MDOP in copolymer starts around $100^{\circ} \mathrm{C}$ and this is similar to thermogravimetric behavior of the PMDOP homopolymer. And the earnest weight loss starts at the lower temperature (around $300^{\circ} \mathrm{C}$ ) compared with that of PVP or PMDOP homopolymer.

The ${ }^{1} \mathrm{H}$ NMR spectra of PVP homopolymer (a) and poly (NVP-co-MDOP) containing $7.6 \mathrm{~mol} \%$ of MDOP in copolymer (b) is shown in Figure 5. In spectrum b, integration of the $-\mathrm{NCH}_{2}$ - peak at $3.24 \mathrm{ppm}$ (PVP) and of the $-\mathrm{CH}_{2} \mathrm{COO}$ - peak at $4.05 \mathrm{ppm}$ (PMDOP) were used to estimate NVP content in the copolymer. The FT-IR spectrum of poly (NVP-co-MDOP) 


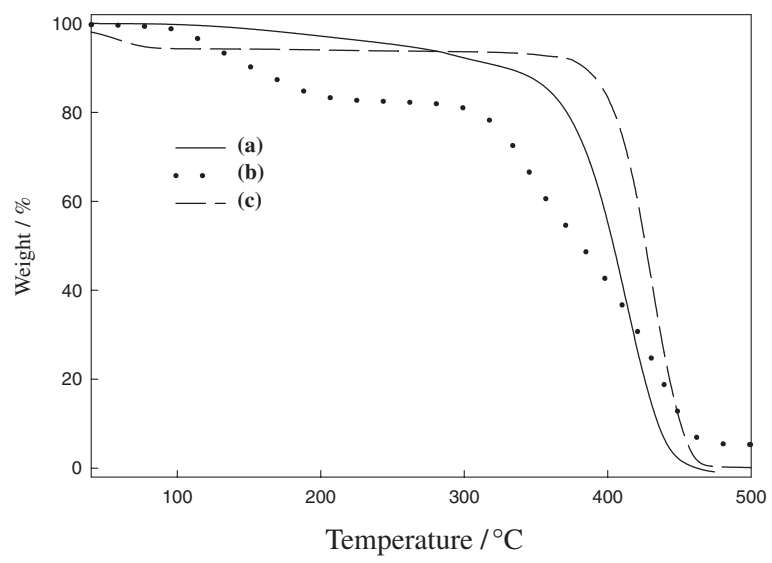

Figure 4. Thermogravimetric analysis curves for: (a) PMDOP, (b) poly(NVPco-MDOP) containing $37.6 \mathrm{~mol} \%$ of PMDOP (c) PVP.
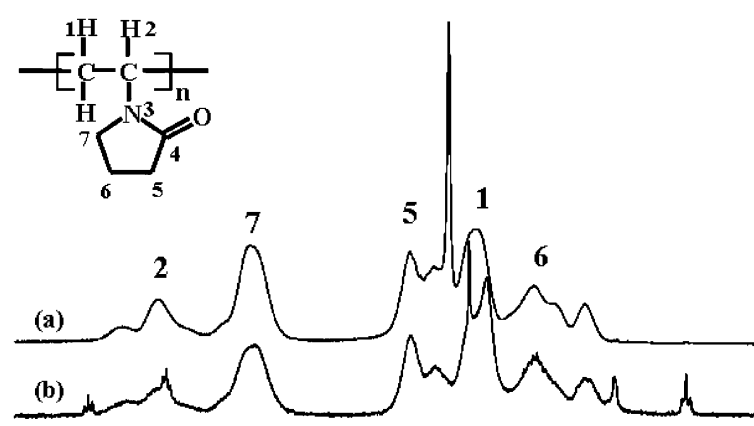

$\delta(\mathrm{ppm})$

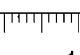

4.0

3.0

2.0

1.0

Figure 5. ${ }^{1} \mathrm{H}$ NMR spectra of NVP homopolymer and copolymer containing $4.4 \mathrm{~mol} \%$ of PMDOP in $\mathrm{CDCl}_{3}$ : (a) PVP, (b) poly(NVP-co-MDOP).

shows a characteristic $\mathrm{C}=\mathrm{O}$ stretching peak at $1730 \mathrm{~cm}^{-1}$ (Figure 6). Copolymer composition data $\left(\mathrm{F}_{\mathrm{NVP}}\right)$ for copolymerization in $\mathrm{CO}_{2}\left(70^{\circ} \mathrm{C} ; 300 \mathrm{bar}\right)$ as a function of NVP monomer feed contents $\left(f_{N V P}\right)$ are shown in Table II. This result is taken to indicate that NVP is generally more reactive than MDOP during the precipitation copolymerization process in $\mathrm{scCO}_{2}$.

\section{Measurement of the Reactivity Ratio of Comonomers}

Typically, because a monomer reactivity ratio is accomplished by performing polymerizations at lowered conversions $(<15 \mathrm{wt} \%),{ }^{34}$ copolymerization of NVP and MDOP was performed in $\mathrm{CO}_{2}$ at low conversion $(<10.3 \mathrm{wt} \%)$ to determine relative monomer reactivity ratios. The effect of the reaction temperature on the comonomer reactivity ratios was also examined at the same $\mathrm{CO}_{2}$ density $(0.788 \mathrm{~g} / \mathrm{mL})$. A summary of these polymerization results is shown in Table III. The reaction time was limited from 40 to $200 \mathrm{~min}$ to obtain low yield. The thermal decomposition rate of $\mathrm{AIBN}$ in $\mathrm{scCO}_{2}$ is lower than that in organic solvent. ${ }^{35}$ Relatively the longer reaction time for low yields than that in typical experiments for measurement of reactivity ratios was needed. The data by calculation of relative integral area by ${ }^{1} \mathrm{H}$ NMR analysis was

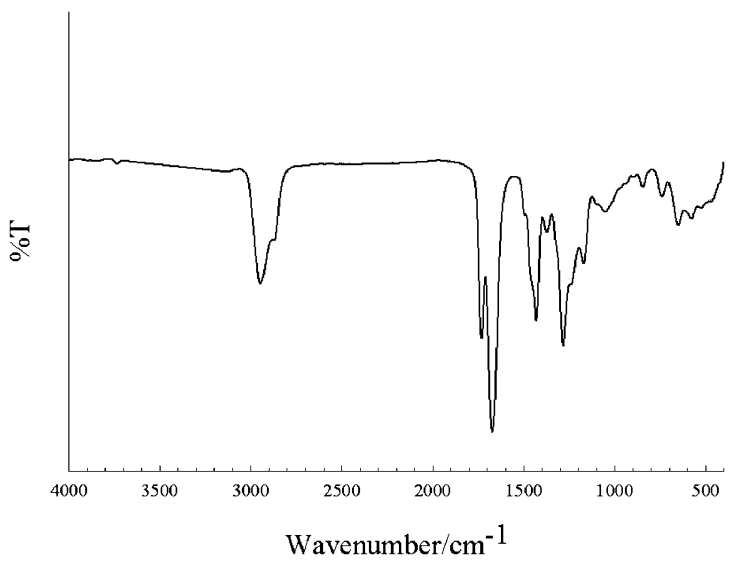

Figure 6. FT-IR spectrum of poly(NVP-co-MDOP).

Table III. Precipitation copolymerization of NVP and MDOP to determine comonomer reactivity ratios at low conversion ${ }^{a}$

\begin{tabular}{rccrrr}
\hline Entry & $\begin{array}{c}\text { Temperature } \\
\left({ }^{\circ} \mathrm{C}\right)\end{array}$ & $\begin{array}{c}\text { NVP in feed } \\
\left(\mathfrak{f}_{\text {NVP }}, \mathrm{mol} \%\right)\end{array}$ & $\begin{array}{c}\text { Reaction time } \\
(\mathrm{min})\end{array}$ & $\begin{array}{r}\text { Yield } \\
(\%)^{\mathrm{b}}\end{array}$ & $\begin{array}{c}\text { NVP in copolymer } \\
\left(\mathrm{F}_{\mathrm{NVP}}, \mathrm{mol} \%\right)^{\mathrm{c}}\end{array}$ \\
\hline 1 & $60 \pm 0.5$ & 85.0 & 80 & 3.9 & 96.8 \\
2 & & 70.4 & 100 & 2.8 & 92.1 \\
3 & & 55.5 & 120 & 3.5 & 90.6 \\
4 & & 43.9 & 180 & 4.3 & 86.0 \\
5 & & 20.6 & 200 & 3.1 & 71.3 \\
6 & $70 \pm 0.5$ & 85.4 & 40 & 7.4 & 97.4 \\
7 & & 70.7 & 60 & 10.3 & 92.9 \\
8 & & 56.0 & 40 & 3.1 & 92.2 \\
9 & & 41.9 & 40 & 3.2 & 86.8 \\
10 & & 20.9 & 60 & 3.5 & 74.5 \\
11 & & 10.7 & 80 & 3.4 & 54.8 \\
\hline
\end{tabular}

a Reaction conditions; total $4.0 \mathrm{~g}$ of comonomer, $1 \mathrm{wt} \%$ of AIBN on comonomer and density of $\mathrm{CO}_{2}$ is $0.788 \mathrm{~g} / \mathrm{ml}$. ${ }^{\mathrm{b}} \mathrm{As}$ determined by gravimetric measurement. ${ }^{\mathrm{c}} \mathrm{As}$ determined by calculation of relative integral area by ${ }^{1} \mathrm{H}$ NMR analysis.

determined to the estimated of composition for copolymers. The reactivity ratio was calculated using the differential form of the Mayo-Lewis equation ${ }^{33,36}$ as follows:

$$
F_{N V P}=\frac{r_{N V P} f_{N V P}^{2}+f_{N V P}\left(1-f_{N V P}\right)}{r_{N V P} f_{N V P}^{2}+2 f_{N V P}\left(1-f_{N V P}\right)+r_{M D O P}\left(1-f_{N V P}\right)^{2}}
$$

The terms of $f_{N V P}$ and $F_{N V P}$ represent the mole fractions of NVP in the feed and in the copolymer, respectively. These data were fitted by nonlinear regression analysis using Mathematica.

Summaries of the experimental $F_{N V P}$ and $f_{N V P}$ data at 60 and $70{ }^{\circ} \mathrm{C}$ are shown in Figure 7 where the solid lines represent the lines of best fit determined by equation 1 . There were no significant changes in either experimental or fitted data for the two different reaction temperatures. The calculated reactivity ratios between the polymerizations at 60 and $70^{\circ} \mathrm{C}$, however, did indicate appreciable differences. The fitted comonomer reactivity ratios from equation 1 are represented in Table IV where $r_{N V P}$ and $r_{M D O P}$ increased as the reaction temperature increased. This was especially noted for $\mathrm{r}_{\mathrm{MDOP}}$ which increased more quickly than did $r_{\mathrm{NVP}}$. A large value of $r_{\mathrm{NVP}}$ compared with $\mathrm{r}_{\mathrm{MDOP}}$ means that NVP is substantially more reactive than MDOP during precipitation polymerization in the $\mathrm{scCO}_{2}$ 
environment. But as increasing reaction temperature the reactivity of MDOP quickly increases and $r_{N V P} r_{M D O P}$ comes close to 1 at $70{ }^{\circ} \mathrm{C}$. $\mathrm{r}_{\mathrm{NVP}} \mathrm{r}_{\mathrm{MDOP}}$ represents the degree of deviation from ideal copolymerization, in which $\mathrm{r}_{\mathrm{NVP}} \mathrm{r}_{\mathrm{MDOP}}=1 .^{31}$ A tendency of large deviation on reactivity ratios in copolymerization with MDOP was also shown in

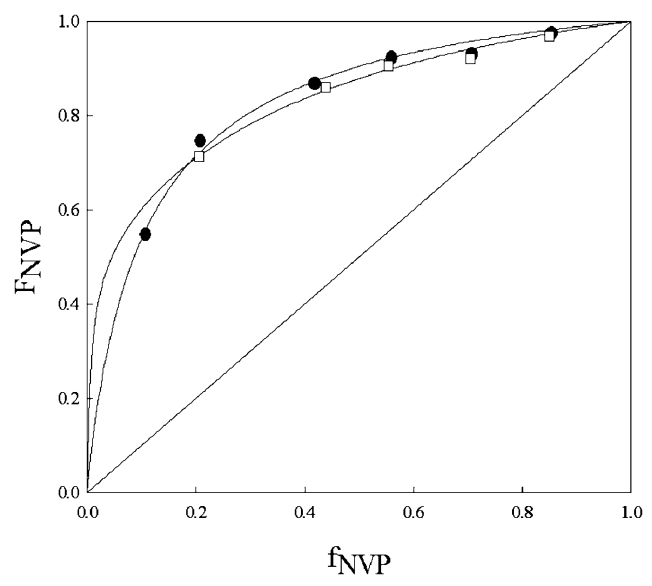

Figure 7. Experimental copolymerization compositions and the predicted curves for the copolymerization of NVP and MDOP in $\mathrm{scCO}_{2}$ showing the effect of temperature: at $60^{\circ} \mathrm{C}$ (open squares) and $70^{\circ} \mathrm{C}$ (filled circles).

Table IV. Reactivity ratios for the copolymerization of NVP and MDOP at 60 and $70^{\circ} \mathrm{C}$

\begin{tabular}{cccc}
\hline Temperature $\left({ }^{\circ} \mathrm{C}\right)$ & $\mathrm{r}_{\mathrm{NVP}}$ & $\mathrm{r}_{\mathrm{MDOP}}$ & $\mathrm{r}_{\mathrm{NVP}} \mathrm{r}_{\mathrm{MDOP}}$ \\
\hline $60 \pm 0.5$ & 6.316 & 0.014 & 0.088 \\
$70 \pm 0.5$ & 9.252 & 0.081 & 0.752 \\
\hline
\end{tabular}

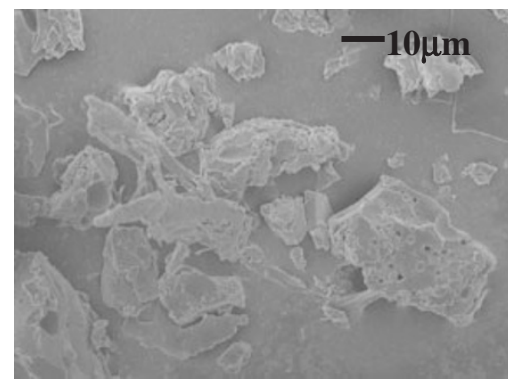

(a)

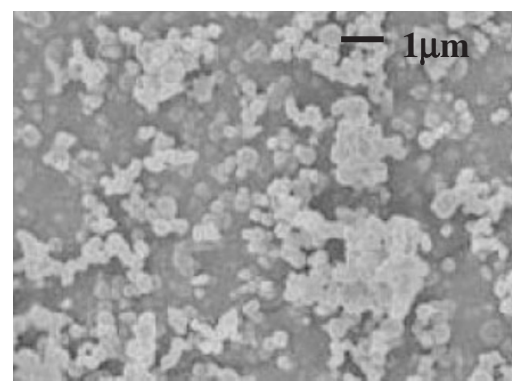

(c) reference data. ${ }^{10,37}$ The reactivity ratio of MDOP in copolymerization with styrene or MMA was much smaller than that of styrene or MMA.

\section{The Preparation of Copolymer Particles using ASES Process: the Effect of Comonomer Concentrations}

ASES experiments were performed at fixed the liquid solution flow rate $(0.5 \mathrm{~mL} / \mathrm{min})$, the solvent flow rate $(3.0$ $\mathrm{kg} / \mathrm{h})$, the pressure $(150 \mathrm{bar})$, the temperature $\left(40^{\circ} \mathrm{C}\right)$, and solution concentration $(0.5 \mathrm{wt} \%)$. The mol \% of MDOP in feed comonomer was varied from 10 to 25 . The results of FE-SEM images are shown in Table $\mathrm{V}$ and Figure 8 . The particle size range after ASES process was from 0.20 to $0.85 \mu \mathrm{m}$. The Mean particle size of polymer particles slightly increased and the morphology of particles were aggregated as MDOP concentration in feed ratio increased. The $T_{\mathrm{g}}$ data of copolymers was decreased (Table II) and the morphology of copolymer became wax-like as the increasing of MDOP contents in copolymer. The lower $T_{\mathrm{g}}$ of copolymer can be attributed to polymer particles being easy to aggregate during reprecipitation of polymer particles in ASES process. The fine particle of

Table V. The experimental conditions of ASES process and mean particle diameter ${ }^{a}$

\begin{tabular}{cccccc}
\hline Entry & $\begin{array}{c}\text { NVP in feed } \\
(\mathrm{mol} \%)\end{array}$ & $\begin{array}{c}\text { MDOP in feed } \\
(\mathrm{mol} \%)\end{array}$ & $\begin{array}{c}\text { Pressure } \\
(\mathrm{bar})\end{array}$ & $\begin{array}{c}\text { Temperature } \\
\left({ }^{\circ} \mathrm{C}\right)\end{array}$ & $\begin{array}{c}\text { Mean particle } \\
\text { diameter }(\mu \mathrm{m})\end{array}$ \\
\hline 1 & 90.1 & 9.9 & & & 0.36 \\
2 & 80.4 & 19.6 & 150 & $40 \pm 0.5$ & 0.41 \\
3 & 75.4 & 24.6 & & & 0.41 \\
\hline
\end{tabular}

${ }^{\mathrm{a}}$ solution flow rate $=0.5 \mathrm{~mL} / \mathrm{min}, \mathrm{CO}_{2}$ flow rate $=3.0 \mathrm{~kg} / \mathrm{h}$, polymer solution concentration $=0.5 \mathrm{wt} \% / \mathrm{DCM}$.

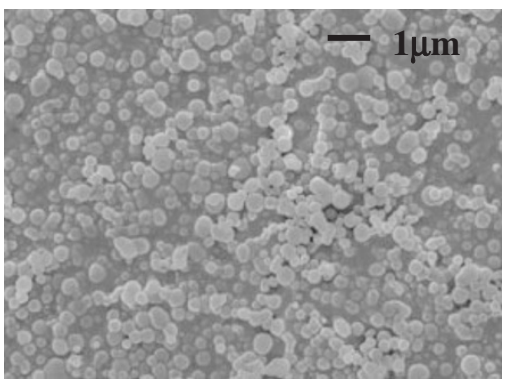

(b)

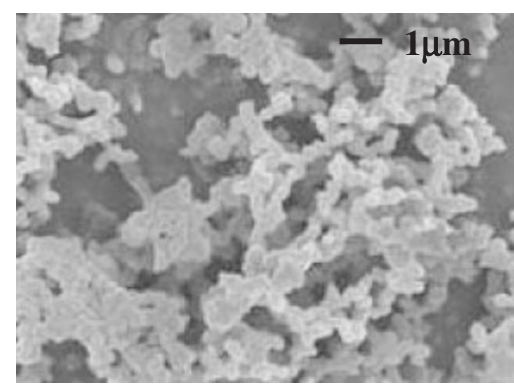

(d)

Figure 8. SEM images of poly(NVP-co-MDOP) particles after ASES process: (a) original copolymer before ASES process, (b) 9.9 mol\%, (c) 19.6 mol \%, (d) $24.6 \mathrm{~mol} \%$ of MDOP in feed comonomer. 
copolymer was not prepared up to $25 \mathrm{~mol} \%$ of MDOP in feed ratio and strongly aggregated.

\section{CONCLUSIONS}

Free radical ring-opening homopolymerization of 2-methylene-1,3-dioxepane (MDOP) was synthesized in $\mathrm{scCO}_{2}$ using a precipitation polymerization method. The homopolymer that resulted was characterized with ${ }^{1} \mathrm{H}$ NMR, FT-IR, DSC and TGA. The data obtained were compared with those available from commercial PCL products and synthesized in bulk phase. The high branching density and low molecular weight of PMDOP polymerized in $\mathrm{scCO}_{2}$ affected decreasing of $T_{\mathrm{g}}$ compared with that reported data. ${ }^{20}$

Precipitation copolymerization of MDOP with NVP was also investigated in $\mathrm{scCO}_{2}$. The structure of the copolymer and the effects of co-monomer ratios on the glass transition temperature and thermal properties were characterized by ${ }^{1} \mathrm{H}$ NMR, FT-IR and DSC. Reactivity ratios of the comonomer in the initial step of the precipitation copolymerization process were estimated from copolymer composition analysis.

We also investigated the effect of reaction temperatures on reactivity ratios. The reactivity ratios were observed to be slightly increased and MDOP demonstrated a larger deviation of reactivity ratios than that of NVP with the increase of temperature.

Copolymer particles obtained from precipitation polymerization in $\mathrm{scCO}_{2}$ were reprecipitated using $\mathrm{scCO}_{2}$ as the antisolvent. The sub-micron sized copolymer particles were prepared after ASES processing and particle size was slightly increased but agglomerated as MDOP contents in feed comonomer ratios increased. Studies involving impregnation of special drugs and release behavior of drugs in this biocompatible and degradable polymer will be the subject of future investigations.

Acknowledgment. The authors gratefully acknowledge the Ministry of Commerce, Industry \& Energy and the Energy Management Corporation for their financial support.

Received: July 4, 2007 Accepted: December 26, 2007 Published: February 15, 2008

\section{REFERENCES}

1. "Handbook of Biodegradable Polymers," A. J. Domb, J. Kost, and D. Wiseman, Ed., Amsterdam, Harwood Academic Publishers, 1997.

2. V. V. Ranade and M. A. Hollinger, "Drug Delivery Systems," New York, CRC Press, 1996.

3. M. Chasin and R. Langer, "Biodegradable Polymers as Drug Delivery
Systems," New York, Marcel Dekker, 1990.

4. T. W. Chung, K. Y. Cho, H. C. Lee, J. W. Nah, J. H. Yeo, T. Akaike, and C. S. Cho, Polymer, 45, 1591 (2004).

5. J. W. Pack, S. H. Kim, I. W. Cho, S. Y. Park, and Y. H. Kim, J. Polym. Sci., Part A: Polym. Chem., 40, 544 (2002).

6. D. D. Hile and M. V. Pishko, Macromol. Rapid Commun., 20, 511 (1999).

7. S. Slomkowski, S. Sosnowski, and M. Gadzinowski, Polym. Degrad. Stab., 59, 153 (1998).

8. K. E. Uhrich, S. M. Cannizzaro, R. S. Langer, and K. M. Shakesheff, Chem. Rev., 99, 3181 (1999).

9. J. Xu, Z. L. Liu, and R. X. Zhuo, J. Appl. Polym. Sci., 103, 1146 (2007).

10. L. F. Sun, R. X. Zhuo, and Z. L. Liu, Macromol. Biosci., 3, 725 (2003).

11. L. F. Sun, R. X. Zhuo, and Z. L. Liu, J. Polym. Sci., Part A: Polym. Chem., 41, 2898 (2003).

12. G. E. Roberts, M. L. Coote, J. P. A. Heuts, L. M. Morris, and T. P. Davis, Macromolecules, 32, 1332 (1999).

13. J. Beckman, J. Supercrit. Fluids, 28, 121 (2004).

14. N. Ajzengerg, F. Trabelsi, and F. Recasens, Chem. Eng. Technol., 23, 829 (2000).

15. A. I. Cooper, J. Master. Chem., 10, 207 (2000).

16. D. Horák, M. Kryśtůfek, and J. Spěváček, J. Polym. Sci., Part A: Polym. Chem., 38, 653 (2000).

17. A. Galia, A. Giaconia, V. Iaia, and G. Filardo, J. Polym. Sci., Part A: Polym. Chem., 42, 173 (2004).

18. J. E. Mark, "Polymer Data Handbook," Oxford University Press, 1999.

19. BASF product literature, "Luviskol ${ }^{\circledR}$ PVP Polymers and Kollidon ${ }^{\circledR}$ PVP Polymers," 1993.

20. S. Jin and K. E. Gonsalves, Macromolecules, 30, 3104 (1997).

21. Y. Zhong, P. F. Wolf, E. G. Malawer, and K. S. Narayanan, United States Patent No. 5912312 (1998).

22. E. Reverchon, J. Supercrit. Fluids, 15, 1 (1999).

23. R. Ghaderi, P. Artursson, and J. Carlfors, Eur. J. Pharm. Sci., 10, 1 (2000).

24. P. Chattopadhyay and R. B. Gupta, Ind. Eng. Chem. Res., 39, 2281 (2000).

25. Z. Knez and E. Weinder, Curr. Opin. Solid State Mater. Sci., 7, 353 (2003).

26. S. Yeo and E. Kiran, J. Supercrit. Fluids, 34, 287 (2005).

27. S. Kwon, W. Bae, and H. Kim, Korean J. Chem. Eng., 21, 910 (2004).

28. S. Kwon, W. Bae, and H. Kim, presented at Proceedings of the International Symposium on Supercritical Fluids, Florida 2005.

29. S. Choi, K. Lee, S. Kwon, and H. Kim, J. Supercrit. Fluids, 37, 287 (2006).

30. S. Jin and K. E. Gonsalves, Macromolecules, 31, 1010 (1998).

31. G. Odian, "Principles of polymerization," 3rd ed., Wiley Interscience, 1991.

32. J. Brandrup, E. H. Immergut, and E. A. Grulke, in "Polymer Handbook," 4th ed., John Wiley \& Sons, Inc, 1999.

33. L. H. Sperling, "Introduction to Polymer Physical Science," 2nd ed, New York, John Wiley \& Sons, 1991.

34. A. L. Polic, T. A. Duever, and A. Penlidis, J. Polym. Sci., Part A: Polym. Chem., 36, 813 (1998).

35. Z. Guan, J. R. Combes, Y. Z. Menceliglu, and J. M. Desimone, Macromolecules, 26, 2663 (1993).

36. B. Baradie and M. S. Shoichet, Macromolecules, 35, 3569 (2002).

37. S. Harrisson and T. P. Davis, Macromolecules, 34, 3869 (2001). 